\title{
Abundance and sources of atmospheric halocarbons in the Eastern Mediterranean
}

Fabian Schoenenberger et al.

Correspondence to: Stephan Henne (stephan.henne@empa.ch)

The copyright of individual parts of the supplement might differ from the CC BY 3.0 License. 
Table S1: Basic statistics for the 3-hourly aggregates of the observations taken at all sites during the campaign period (Dec. 2012 - Aug.2013). Observation sites are: Finokalia (FKL), Jungfraujoch (JFJ), Mace Head (MHD), Monte Cimone (CMN). Shown are the number of observations $(\mathrm{N})$, the mean, minimum (Min), maximum (Max) and standard deviation (SD) for the observations and the baseline values, estimated with REBS. The mean measurement uncertainty $\left(\sigma_{0}\right)$ was determined from the standard deviation of reference gas measurements and the baseline uncertainty $\left(\sigma_{b}\right)$ was derived as one constant value by the REBS method.

\begin{tabular}{|c|c|c|c|c|c|c|c|c|c|c|c|}
\hline & \multirow[b]{2}{*}{ Site } & \multirow[b]{2}{*}{$\mathbf{N}$} & \multicolumn{5}{|c|}{ Observations } & \multicolumn{4}{|c|}{ Background (REBS) } \\
\hline & & & $\begin{array}{c}\text { Mean } \\
\text { [ppt] }\end{array}$ & $\begin{array}{c}\text { Min } \\
\text { [ppt] }\end{array}$ & $\begin{array}{c}\text { Max } \\
\text { [ppt] }\end{array}$ & $\begin{array}{c}\text { SD } \\
\text { [ppt] }\end{array}$ & $\begin{array}{c}\sigma_{o} \\
{[p p t]}\end{array}$ & $\begin{array}{c}\text { Mean } \\
\text { [ppt] }\end{array}$ & $\begin{array}{c}\text { Min } \\
\text { [ppt] }\end{array}$ & $\begin{array}{c}\text { Max } \\
\text { [ppt] }\end{array}$ & $\begin{array}{c}\sigma_{b} \\
{[p p t]}\end{array}$ \\
\hline \multirow{4}{*}{ 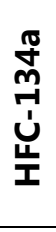 } & FKL & 1467 & 80.8 & 72.8 & 94.2 & 3.4 & 0.8 & 79.7 & 77.2 & 83.0 & 1.9 \\
\hline & JFJ & 1383 & 80.7 & 70.9 & 119.3 & 5.3 & 0.2 & 77.0 & 74.6 & 79.1 & 1.3 \\
\hline & $\mathrm{MHD}$ & 1533 & 80.3 & 73.5 & 122.0 & 5.6 & 0.2 & 77.4 & 76.3 & 78.9 & 0.7 \\
\hline & $\mathrm{CMN}$ & 1040 & 86.1 & 72.8 & 129.3 & 8.7 & 0.3 & 80.1 & 76.2 & 83.1 & 1.7 \\
\hline \multirow{4}{*}{ 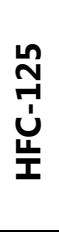 } & FKL & 1193 & 15.9 & 12.8 & 22.3 & 1.3 & 0.4 & 15.3 & 14.1 & 16.1 & 0.6 \\
\hline & JFJ & 1373 & 16.1 & 13.3 & 26.9 & 1.7 & 0.1 & 14.9 & 14.1 & 15.7 & 0.3 \\
\hline & $\mathrm{MHD}$ & 1514 & 15.8 & 13.9 & 28.1 & 1.7 & 0.1 & 14.9 & 14.5 & 15.4 & 0.2 \\
\hline & $\mathrm{CMN}$ & 1078 & 17.6 & 13.4 & 33.3 & 2.6 & 0.1 & 15.8 & 14.6 & 16.8 & 0.6 \\
\hline \multirow{4}{*}{$\begin{array}{l}\text { Ñ } \\
\text { ஸे } \\
\text { ن் } \\
\text { પ્પ }\end{array}$} & FKL & 1428 & 11.5 & 7.8 & 19.3 & 1.6 & 0.2 & 10.6 & 10.3 & 10.7 & 0.8 \\
\hline & JFJ & 1395 & 10.8 & 6.9 & 25.0 & 1.7 & 0.1 & 10.0 & 9.4 & 10.5 & 0.8 \\
\hline & MHD & 1527 & 10.9 & 8.4 & 15.0 & 0.9 & 0.1 & 10.6 & 9.7 & 10.8 & 0.4 \\
\hline & $\mathrm{CMN}$ & 1096 & 11.7 & 7.3 & 21.6 & 1.9 & 0.1 & 10.3 & 9.7 & 10.7 & 0.7 \\
\hline \multirow{4}{*}{ 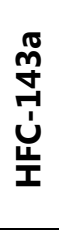 } & FKL & 1252 & 17.4 & 13.2 & 29.6 & 2.2 & 1.2 & 16.3 & 15.8 & 16.7 & 0.9 \\
\hline & JFJ & 1411 & 16.7 & 13.7 & 25.6 & 1.6 & 0.1 & 15.4 & 14.5 & 16.0 & 0.3 \\
\hline & MHD & 1540 & 16.6 & 14.8 & 27.6 & 1.8 & 0.1 & 15.5 & 15.3 & 15.9 & 0.2 \\
\hline & $\mathrm{CMN}$ & 1055 & 17.5 & 14.2 & 27.1 & 1.9 & 0.1 & 16.0 & 15.1 & 16.8 & 0.5 \\
\hline \multirow{4}{*}{ 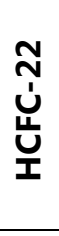 } & FKL & 1438 & 235.8 & 226.9 & 271.6 & 3.5 & 1.8 & 234.7 & 233.0 & 237.9 & 2.3 \\
\hline & JFJ & 1389 & 234.9 & 224.9 & 252.4 & 2.9 & 0.6 & 234.2 & 233.0 & 236.3 & 2.2 \\
\hline & MHD & 1523 & 235.8 & 230.3 & 259.8 & 1.8 & 0.6 & 235.2 & 235.0 & 236.0 & 1.1 \\
\hline & $\mathrm{CMN}$ & 980 & 235.1 & 225.2 & 255.5 & 3.3 & 0.7 & 234.0 & 232.2 & 235.8 & 1.9 \\
\hline \multirow{4}{*}{ 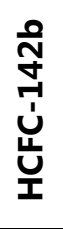 } & FKL & 1075 & 23.9 & 21.3 & 27.2 & 0.9 & 0.6 & 23.7 & 22.6 & 24.5 & 0.5 \\
\hline & JFJ & 1392 & 23.4 & 22.4 & 26.1 & 0.4 & 0.1 & 23.2 & 23.1 & 23.4 & 0.2 \\
\hline & MHD & 1533 & 23.3 & 22.7 & 24.7 & 0.2 & 0.1 & 23.2 & 23.1 & 23.3 & 0.1 \\
\hline & $\mathrm{CMN}$ & 1046 & 23.8 & 22.5 & 26.8 & 0.5 & 0.1 & 23.5 & 23.2 & 23.8 & 0.3 \\
\hline
\end{tabular}


Table S2: Inversion performance of the base inversion and the sensitivity inversions S-ML and S-MS for HFC-134a at Finokalia (FKL), Jungfraujoch (JFJ), Mace Head (MHD) and Monte Cimone (CMN). $N$ is the number of observations used for the inversion. RMSE is the root mean square error in ppt (parts per billion $10^{-12}$ ). $R^{2}$ denotes the coefficient of determination of the complete signals and $R^{2}$ abg is the coefficient of determination of the signals above background. TSS shows the Taylor Skill Score of the entire signal.

\begin{tabular}{|c|c|c|c|c|c|c|c|c|c|c|}
\hline & \multirow[t]{2}{*}{ Site } & \multirow[t]{2}{*}{$N$} & \multicolumn{2}{|c|}{ RMSE } & \multicolumn{2}{|c|}{$\mathrm{R}^{2}$} & \multicolumn{2}{|c|}{$\mathrm{R}^{2}{ }_{\mathrm{abg}}$} & \multicolumn{2}{|c|}{ TSS } \\
\hline & & & apriori & apost & prior & post & prior & post & prior & post \\
\hline \multirow{4}{*}{$\underset{\infty}{\tilde{n}}$} & $\mathrm{FKL}$ & 1421 & 4.7 & 1.7 & 0.41 & 0.74 & 0.20 & 0.29 & 0.86 & 0.95 \\
\hline & JFJ & 1946 & 4.5 & 3.6 & 0.33 & 0.50 & 0.25 & 0.34 & 0.82 & 0.71 \\
\hline & MHD & 2005 & 3.3 & 2.9 & 0.61 & 0.74 & 0.61 & 0.73 & 0.93 & 0.75 \\
\hline & CMN & 1801 & 5.8 & 5.1 & 0.39 & 0.54 & 0.25 & 0.28 & 0.62 & 0.74 \\
\hline \multirow{4}{*}{$\sum_{i}$} & FKL & 1421 & 4.7 & 1.7 & 0.41 & 0.75 & 0.20 & 0.28 & 0.86 & 0.95 \\
\hline & JFJ & 1946 & 4.5 & 3.6 & 0.33 & 0.50 & 0.25 & 0.32 & 0.82 & 0.68 \\
\hline & MHD & 2005 & 3.3 & 3.3 & 0.61 & 0.68 & 0.61 & 0.68 & 0.93 & 0.66 \\
\hline & CMN & 1801 & 5.8 & 5.1 & 0.39 & 0.55 & 0.25 & 0.28 & 0.62 & 0.73 \\
\hline \multirow{4}{*}{$\sum_{i}^{n}$} & FKL & 1421 & 4.7 & 1.7 & 0.41 & 0.75 & 0.20 & 0.36 & 0.86 & 0.97 \\
\hline & JFJ & 1946 & 4.5 & 3.4 & 0.33 & 0.53 & 0.25 & 0.4 & 0.82 & 0.80 \\
\hline & MHD & 2005 & 3.3 & 2.5 & 0.61 & 0.76 & 0.61 & 0.75 & 0.93 & 0.90 \\
\hline & $\mathrm{CMN}$ & 1801 & 5.8 & 5.0 & 0.39 & 0.55 & 0.25 & 0.31 & 0.62 & 0.78 \\
\hline
\end{tabular}




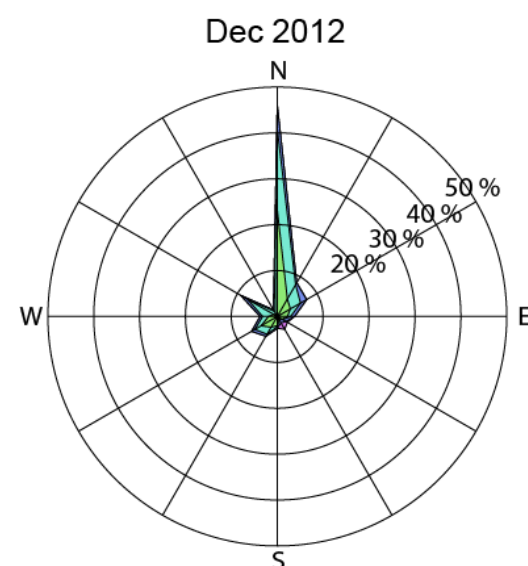

Mar 2012

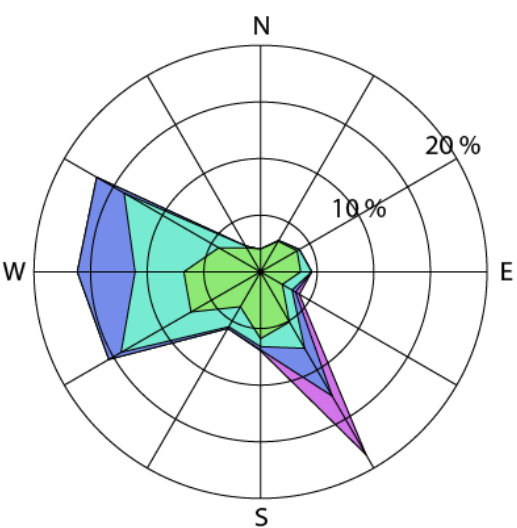

Jun 2013
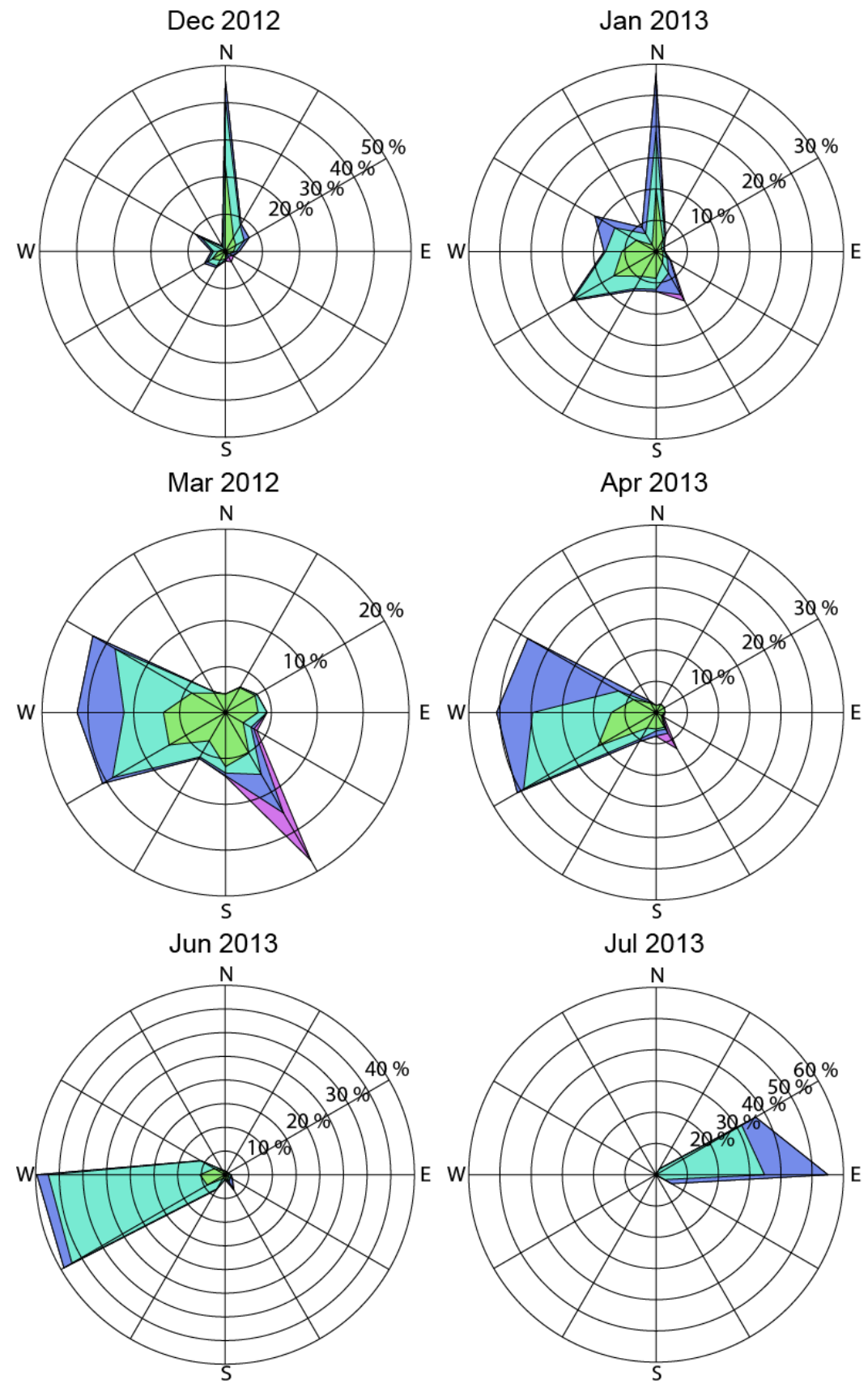

Apr 2013

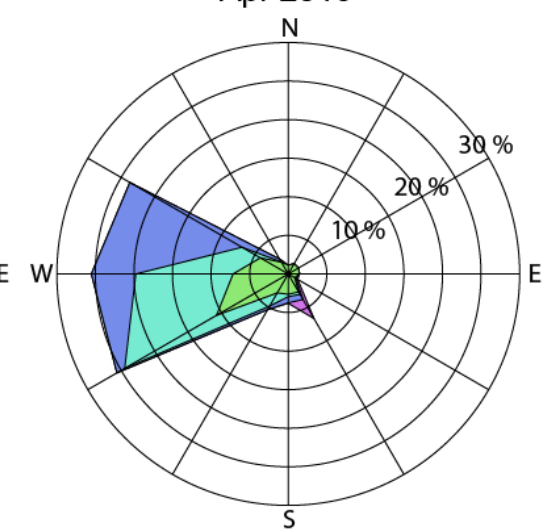

Jul 2013
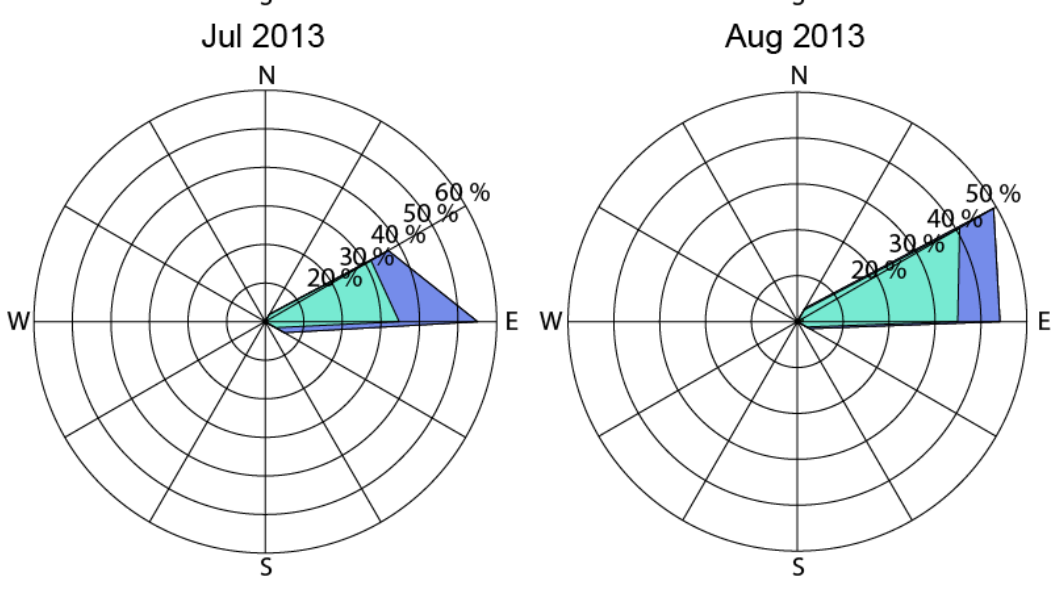

Feb 2013

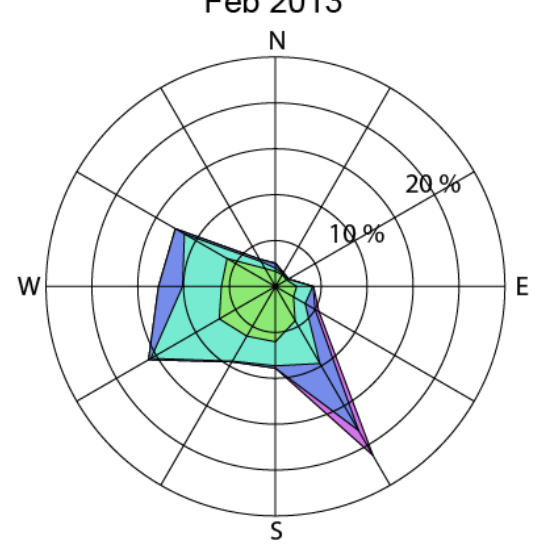

May 2013

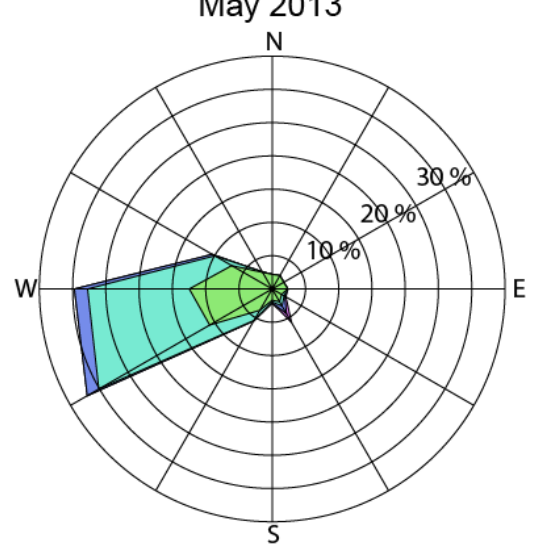

Wind Speed $\left(\mathrm{ms}^{-1}\right): \square 0-5 \quad \square 5-10 \quad \square 10-20 \quad \square>20$

Figure S1: Observed monthly wind roses at Finokalia for the period January to August 2013 showing the directional frequencies colour-coded by wind speed based on 5 minute temporal resolution. Wind data were provided by the University of Crete. 


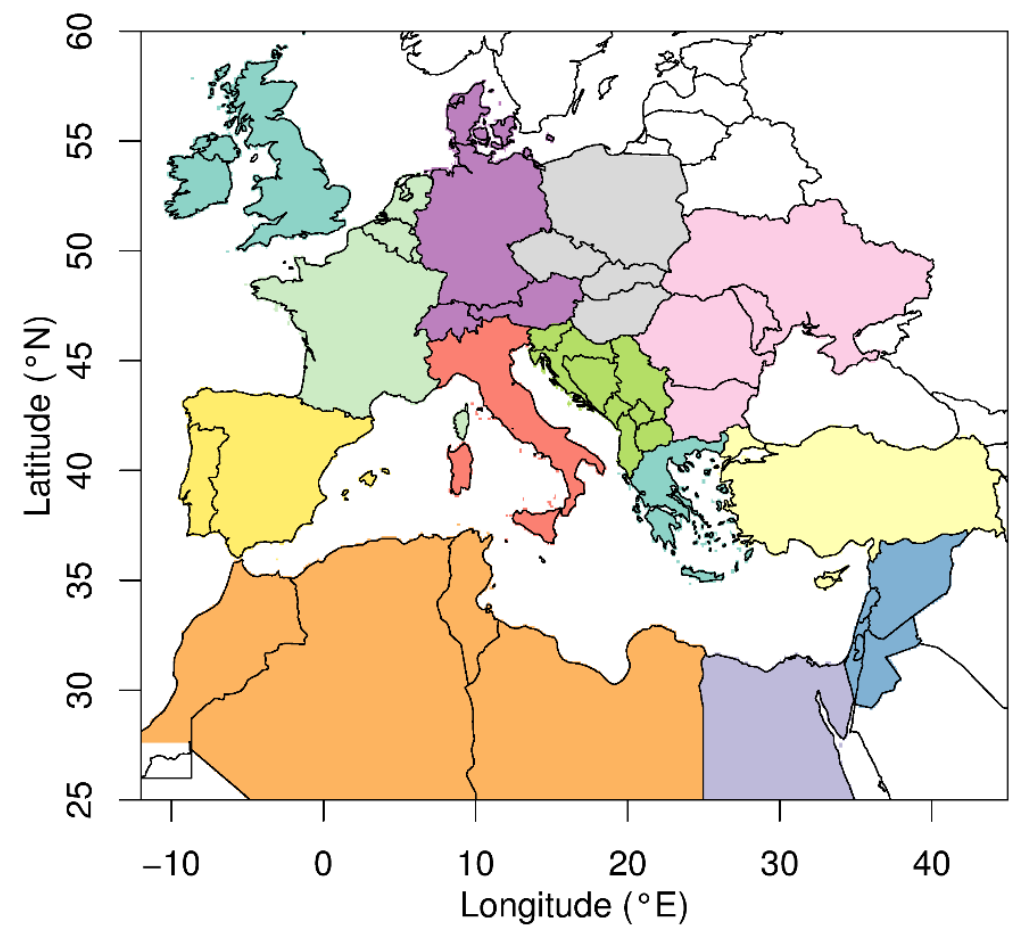

Figure S2: Illustration of region definition used in the discussion of emission estimates: Greece (light turquoise), Turkey (Turkey, Cyprus; pale yellow), Balkans (Serbia, Montenegro, Kosovo, Albania, Bosnia and Herzegovina, Croatia, Slovenia, Former Yugoslav Republic of Macedonia (FYROM); light green), Eastern (Ukraine, Romania, Moldova, Bulgaria; pale pink), Middle East (Jordan, Lebanon, Syria, Palestine, Israel; blue), Egypt (pale purple), Maghreb (Morocco, Algeria, Tunisia, Libya; orange), Central E (Poland, Slovakia, Czech-Republic, Hungary; grey), Central W (Switzerland, Liechtenstein, Germany, Austria, Denmark; purple), Western (France, Luxembourg, Netherlands, Belgium; pale green), Italy (red), Iberian Peninsula (Spain, Portugal; yellow), British Isles (Ireland, United Kingdom; light turquoise). 


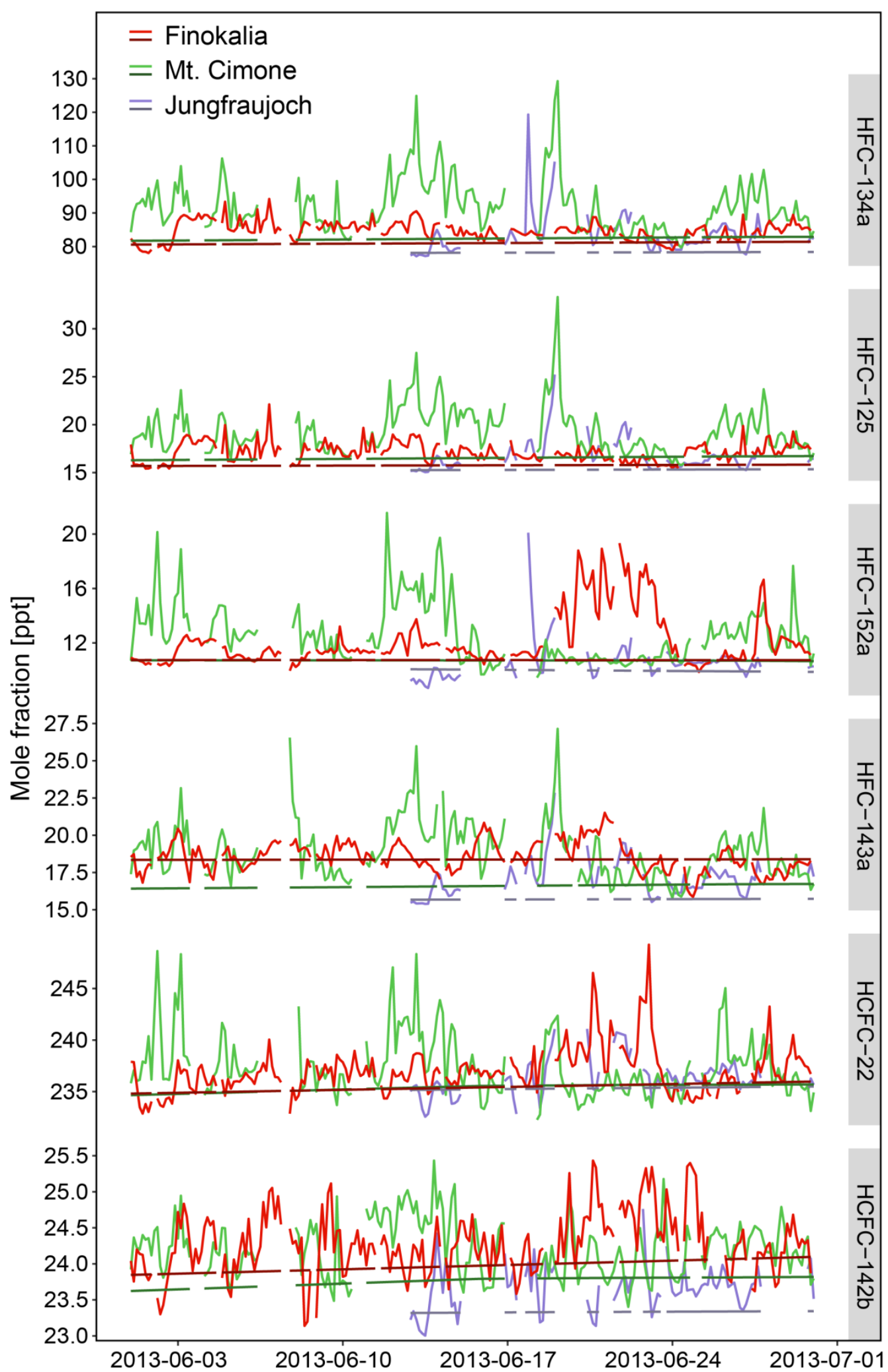

Figure S3: Halocarbon observations in June 2013 at Finokalia (red) and simultaneous measurements at Jungfraujoch (purple) and Monte Cimone (green). The corresponding background estimated with REBS is shown in the darker shade of the respective color. 


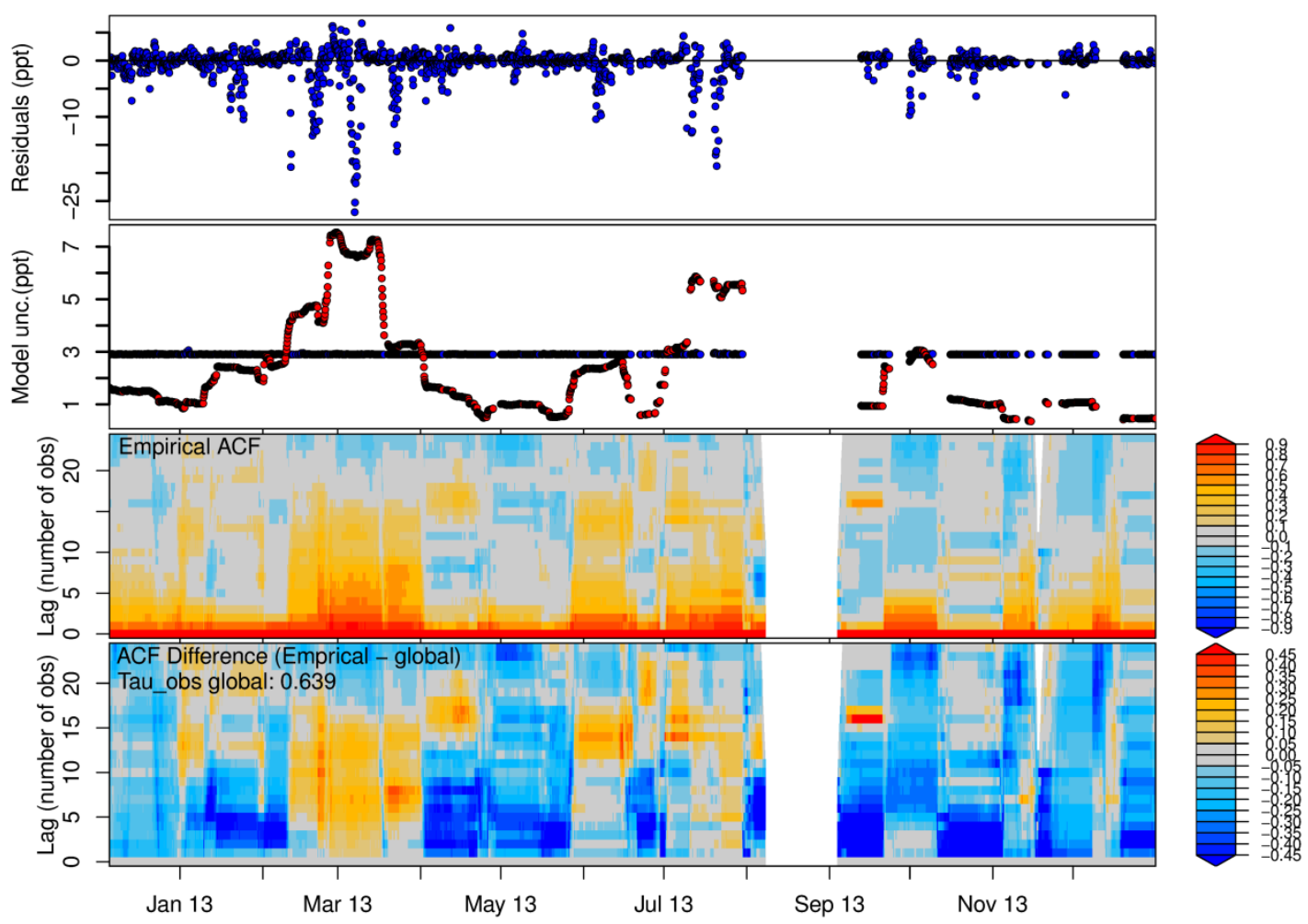

Figure S4: Time series of a) "prior” model residuals, b) data-mismatch uncertainty, blue symbols $\sigma_{c}$, and running RMS, red symbols, c) empirical auto correlation function based on 10 day moving window, d) difference between empirical ACF and fitted auto correlation function with constant (global) correlation length scale. All given for the site MHD and for HFC-134a. 


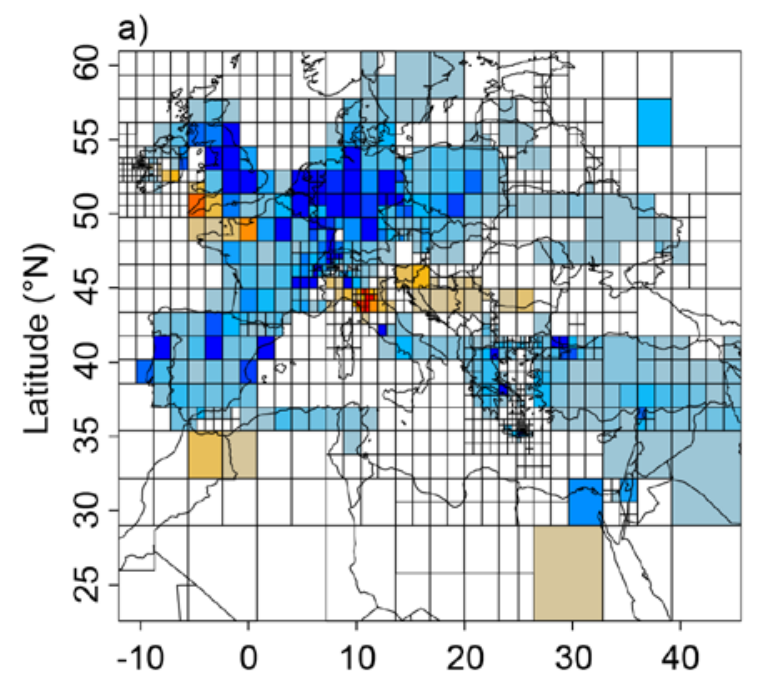

b)

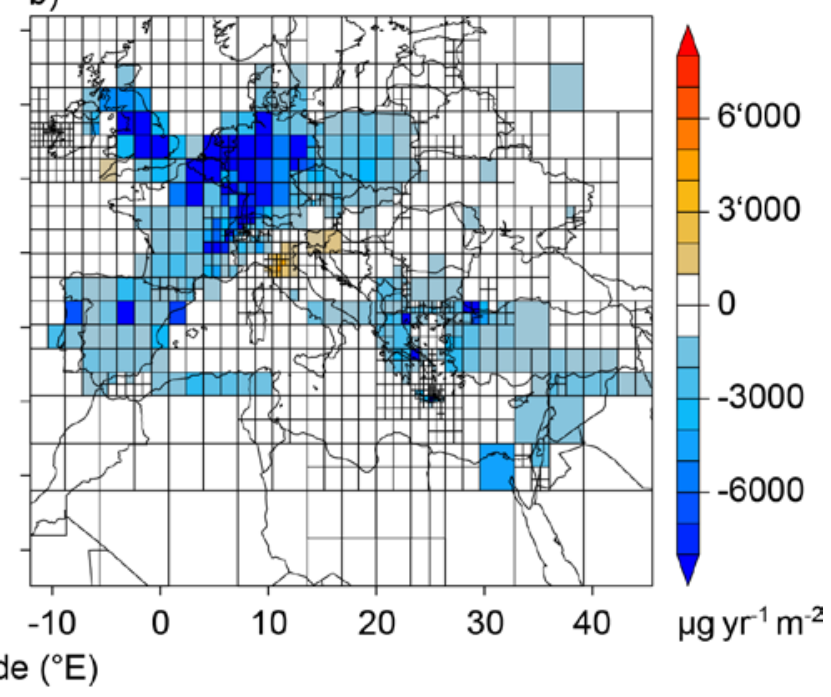

c)

Longitude $\left({ }^{\circ} \mathrm{E}\right)$

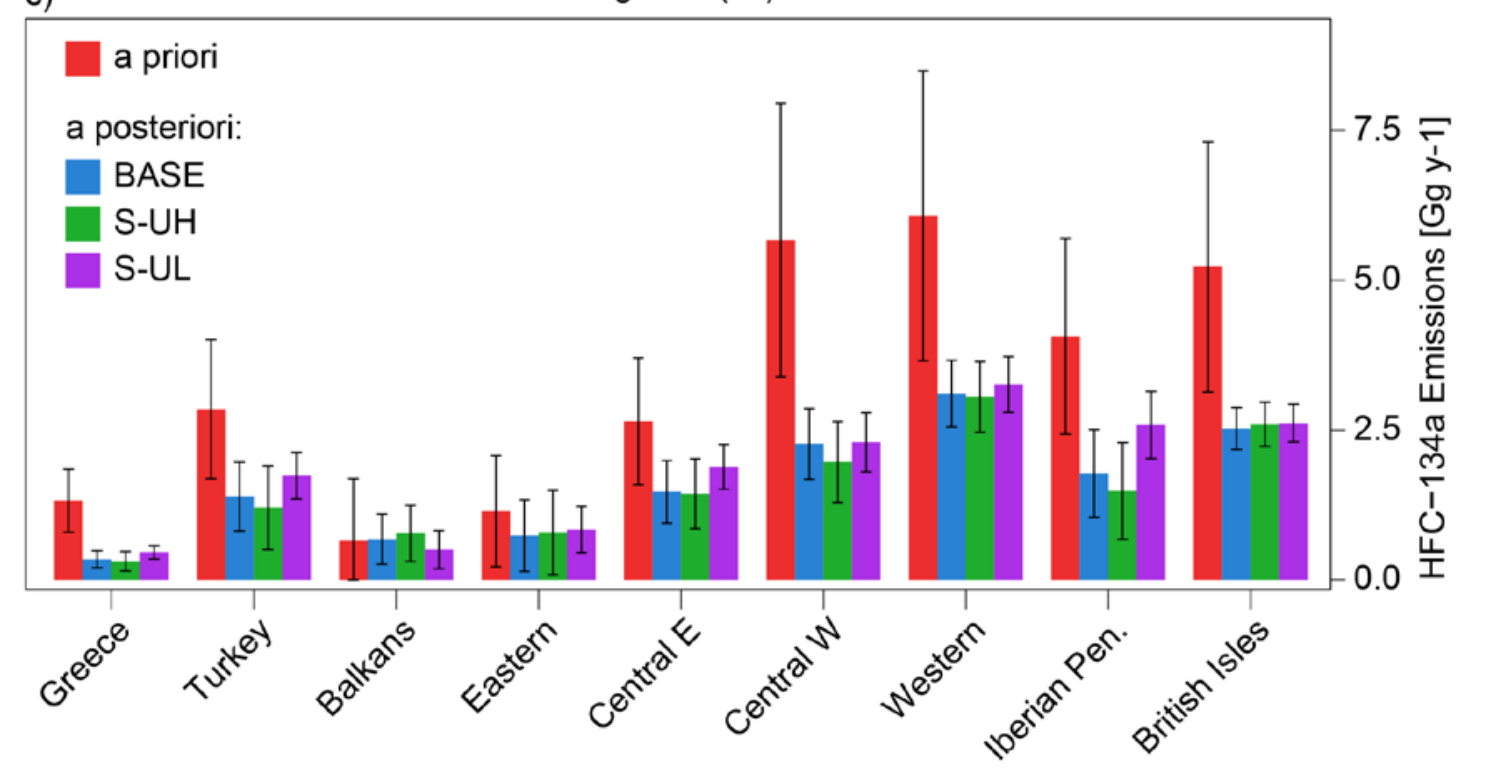

Figure S5: Difference of the a posteriori and a priori emissions for (a) the S-UH and (b) the S-UL inversions. (c) regional emission estimates: a priori emissions (red) and a posteriori emissions $(B A S E=$ blue, $\mathrm{S}-\mathrm{UH}=$ green, $\mathrm{S}-\mathrm{UL}=$ purple). The uncertainties given are two standard deviations of the analytic uncertainty assigned to the a priori emissions and derived by the inversion as a posteriori uncertainties. 

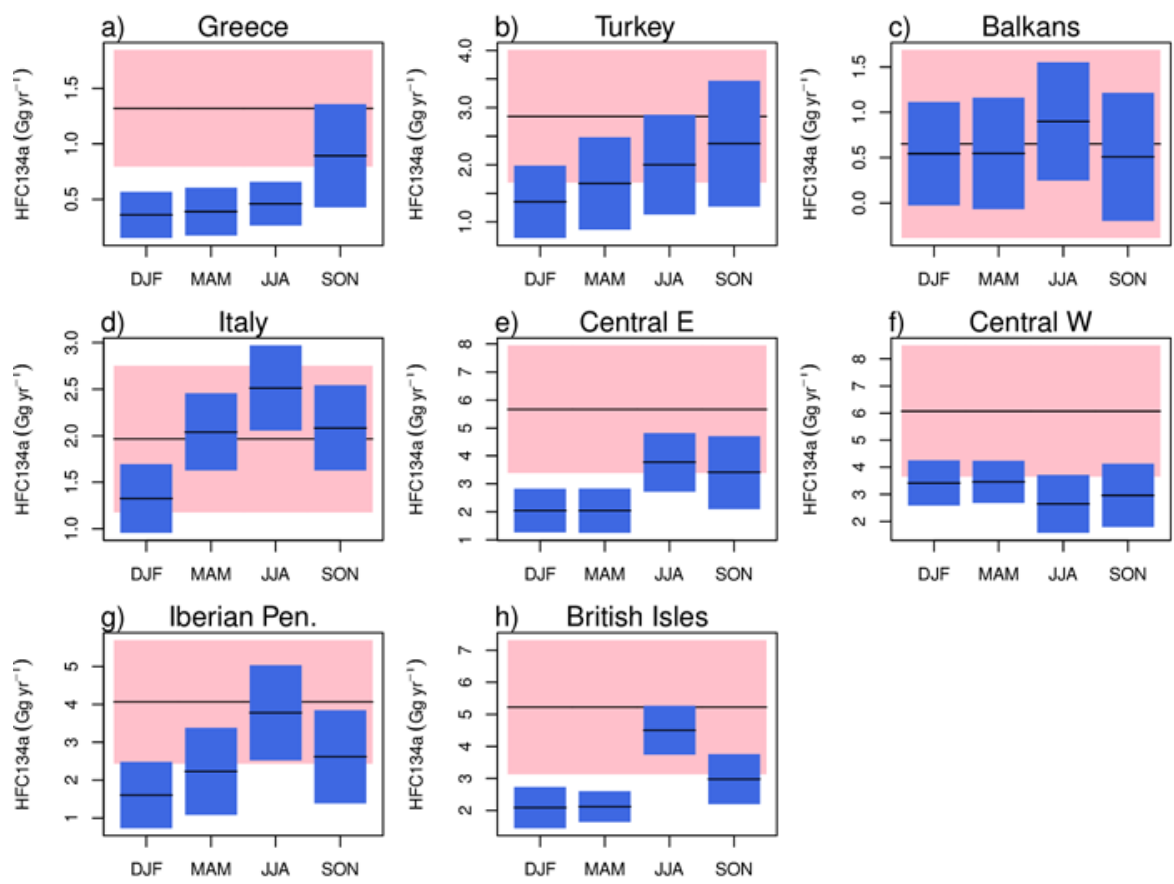

Figure S6: Seasonality of regional HFC-134a emission estimates: (red bars) a-priori and (blue bars) a posteriori emissions. The black lines give the mean estimates and the bars denote the uncertainty (1- $\sigma$ level). 